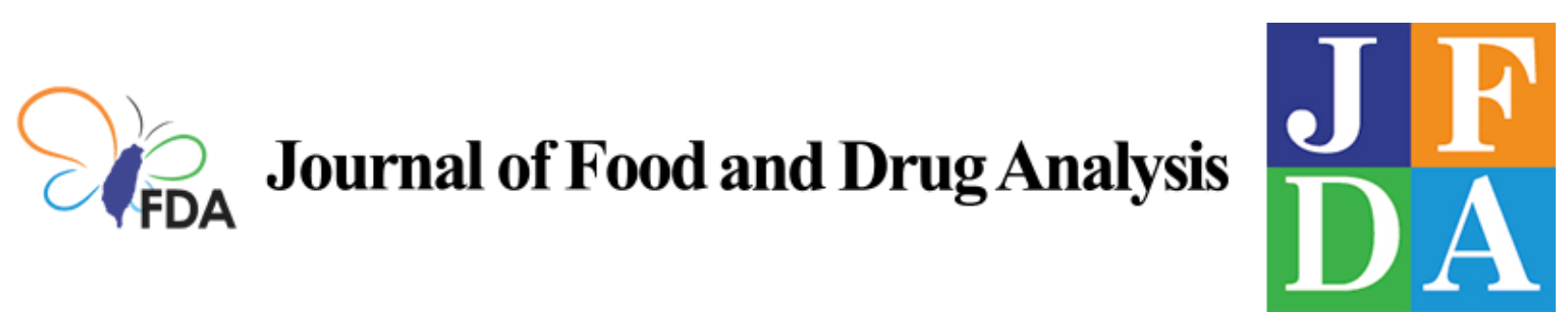

Volume 29 | Issue 2

Article 2

2021

\title{
Human breast milk-based nutritherapy: A blueprint for pediatric healthcare
}

Follow this and additional works at: https://www.jfda-online.com/journal

Part of the Food Science Commons, Medicinal Chemistry and Pharmaceutics Commons, Pharmacology Commons, and the Toxicology Commons

(c) (i) (8)

This work is licensed under a Creative Commons Attribution-Noncommercial-No Derivative Works 4.0 License.

\section{Recommended Citation}

Shende, Pravin and Khanolkar, Bhakti (2021) "Human breast milk-based nutritherapy: A blueprint for pediatric healthcare," Journal of Food and Drug Analysis: Vol. 29 : Iss. 2 , Article 2.

Available at: https://doi.org/10.38212/2224-6614.3352

This Review Article is brought to you for free and open access by Journal of Food and Drug Analysis. It has been accepted for inclusion in Journal of Food and Drug Analysis by an authorized editor of Journal of Food and Drug Analysis. 


\title{
Human breast milk-based nutritherapy: A blueprint for pediatric healthcare
}

\author{
Pravin Shende*, Bhakti Khanolkar
}

Shobhaben Pratapbhai Patel School of Pharmacy and Technology Management, SVKM'S NMIMS, V.L. Mehta Road, Vile Parle (W), Mumbai, India

\begin{abstract}
Human Breast Milk (HBM) is a storehouse of micronutrients, macronutrients, immune factors, microbiota and numerous other bioactive macromolecules. Fulfilment of optimum nutritional requirements of more than 240 million malnourished infants worldwide is possible via adequate amount $(570-900 \mathrm{~mL} / \mathrm{d})$ of breast milk administration to infants in first few years of life. Technological advancements enable study of multiple components of HBM like stem cells, bioactive proteins, micro RNAs, immunoglobulins and epithelial cells to understand their role in enhancement of nutritional value of HBM. Furthermore, immunological and protective functions of HBM against various illnesses like diabetes, anemia, respiratory and cardiovascular abnormalities, otitis media and gastrointestinal diseases prove superiority of HBM over artificial milk. Presence of major macronutrients like fatty acids, sphingomyelins, proteins, peptides, lactoferrin, lactalbumins, lysozymes, mucins, growth factors, oligosaccharides and cytokines increase nutritive value of HBM. In the future, HBM can serve as a carrier for delivery of drugs, vaccines and genes to infants and offer novel therapeutic applications to stimulate effective health, growth and development of infants. The review article highlights multimodal nutritional benefits of HBM, provides insight into preclinical and clinical studies of HBM-based therapeutics and encourages further research on HBM therapy to suffice nutritional needs of infants.
\end{abstract}

Keywords: Clinical studies, Human breast milk, Nutritherapy, Pediatric nutrition, Therapeutic applications

\section{Introduction}

\section{A} dequate nutrition (60-95 g/d carbohydrates, 9.1-11 g/d proteins, 30-31 g/d fats 200-1000 IU, $10 \mu \mathrm{g}-10 \mathrm{mg} / \mathrm{d}$ vitamins and 0.27-40 $\mathrm{mg} / \mathrm{d}$ iron) for infants is essential for their optimal growth and development, whereas poor nutrition enhances risk of multiple diseases and disorders like throat infections, bronchitis, skin diseases, bacterial sinusitis, etc. [1]. Globally, malnutrition is the cause of $45 \%$ of deaths in children $(<5$ years-of-age) and its severe social, economic and health effects pose long-lasting negative impact on many communities and countries. World Health Organization (WHO) recommends prioritization of breastfeeding (administration of HBM) to infants ( $<6$ months- of-age), followed by complementary foods (for infants who are 6-23 months-of-age) to overcome malnutrition [2]. In addition to supply of nutrition, breast milk (BM) shows potential to save lives of 820,000 infants ( $<5$ years-of-age) per year, worldwide [3]. HBM consists of a spectacular array of molecular and cellular components to facilitate optimum nutrition, growth and development of infants [4]. Colostrum renders multitude of nutritional, bioactive and immune factors to provide well-balanced nutrition and protect infants against pathogens. Full-term HBM (THBM) provides components like fats (stimulate cognitive functions), peptides such as ghrelin (controls appetite for long-time), sugars such as oligosaccharides (act against pathogens and increase the production of beneficial bacteria) and

Received 22 January 2021; accepted 25 February 2021.

Available online 15 June 2021.

* Corresponding author at: Fax: +91 2226185422

E-mail address: shendepravin94@gmail.com (P. Shende). 
more than 900 types of proteins (for protective functions) to promote adequate nutrition in infants [5]. HBM is a dynamic fluid consisting of multiple vitamins (A, D, B12, B2, B6 and iodine), minerals, microbiota, micro RNAs (miRNAs), immunoglobulins, antibodies, enzymes, bioactive molecules and viable cells (stem cells, immune cells and milk-producing cells) to suffice nutritional requirements of infants [6]. The advancement in drug, vaccine and gene delivery technologies for administration of medicines to infants via HBM cells [7] will ensure specific therapeutic effect at desirable sites of action with lesser adverse events and more biocompatible nature. The present review article focusses on manifold benefits of HBM-based nutritherapy in the treatment of pediatric illnesses and explores various possibilities for modulation of breast milk components for HBM-based drug delivery to infants.

\section{Health burden associated with pediatric nutrition}

Malnutrition in infants is a major contributor to mortality of infants as they are more susceptible to infections, immune-related disorders (hypersensitivity reactions, neoplasia, eczema, contact dermatitis) and other respiratory and gastrointestinal illnesses [2]. Since the complications of chronic malnutrition in infants are irreparable, addressing intergenerational transmission of malnutrition within first two years (after birth) is essential. Triple burden of malnutrition (undernutrition, overweight and hidden hunger) is harmful to children as well as mothers [3]. Undernutrition includes stunting and wasting which results in poor growth and cognition, susceptibility to infections, perinatal complications, chronic diseases and low birth weight of infants. The overweight and obese infants are prone to diabetes, cardiovascular problems, metabolic disorders and obstetric complications [1,3]. Deficiency of micronutrients is the cause for hidden hunger that manifests neural tube abnormalities in neonates, maternal morbidity and mortality, impaired cognition, poor immunity and improper tissue and organ development [8]. According to United Nations Children's Fund [3] around 149 million children $(<5$ years-of-age) are stunted, 50 million wasted and 40 million are overweight, where more than 1 in 3 children experience improper growth due to inadequate nutrition. Globally, $21.3 \% \quad(<5$ years-of-age) children suffer from stunting, 6.9\% from wasting and severe wasting and $5.6 \%$ from obesity [9].

Children with short height endure weight loss in early childhood and fail to attain adequate size (Body Mass Index: 18.5-24.9) as adults, resulting in lesser physical capacity to carry out day-to-day activities, lower IQ ( $<90$ score) and higher susceptibility to infections as compared to normal children (who receive adequate neonatal nutrition) [10]. Breastfeeding exhibits numerous benefits for infants especially in the first hour after birth, therefore, such infants show lower mortality and morbidity rates in comparison to non-breastfed and latebreastfed infants [11]. Despite such prominent benefits of administration of HBM, only $44 \%$ (two out of five) infants are breast-fed in the first hour (after birth) and $42 \%$ infants ( $<6$ months-of-age) are exclusively breastfed [9]. Increase in promotion of breast milk substitutes (BMS), the presence of cultural and social taboos against breastfeeding, lack of balance between work and childcare by mothers and insufficient support for breastfeeding are the main reasons for lower rate of breastfeeding to infants universally [12]. Low birth weight (below $2.5 \mathrm{~kg}$ body weight), very low birth weight (1-1.5 kg) and extremely low birth weight (below $1 \mathrm{~kg}$ ) infants suffer from serious nutritional deficiencies due to immature development of tissue and organ systems. Nutrient absorption from gastrointestinal tract (GIT) and digestion and absorption of fat-soluble vitamins, trace elements and fats are primarily damaged in such infants [13]. Brain, kidney and liver are vulnerable to detrimental effects of insufficient nutrition, followed by impairment of overall growth and development of infants. Energy requirements are more in immature infants as their needs of incidental cold stress, resting metabolic rates and losses of unabsorbed nutrients are higher [14]. Insufficient amount and lower quality of proteins administered to low birth weight (LBW) infants can impair their renal functions. Disruption in maintenance of water and energy balance, insufficient supply of optimum amounts of proteins, vitamins and minerals and dysregulation of calcium-phosphorus homeostasis are some deleterious effects of inadequate administration of macronutrients (in form of HBM) to infants [15].

\section{Therapeutic applications of HBM}

HBM is classified into three types: 1 . Colostrum, 2. Transitional milk and 3. Mature milk, where each type possesses distinct characteristics (colostrum: composed of minerals, proteins, vitamins and 
immunoglobulins, transitional milk: contains proteins and calories and mature milk: consists of $90 \%$ water and $10 \%$ proteins, fats and carbohydrates). The composition of HBM changes during the course of lactation period to facilitate effective nutritional requirements for infants at all ages (Fig. 1) [16]. Around $87 \%$ water, $7 \%$ lactose, $4 \%$ fat, $1 \%$ proteins and small amounts of carbohydrates and vitamins are nutritional components of HBM, whereas its non-nutritional constituents are hormones and growth factors [15]. In addition to supply of nutrition, milk therapy using HBM demonstrates immunological and protective properties to protect infants from $H$. pylori infections, immunodeficiencyrelated diarrhoea, anemia, irregular tissue growth, respiratory and cardiovascular abnormalities, enteral nervous system and autoimmune disorders, inadequate intestinal maturation and gastrointestinal diseases. Furthermore, HBM plays an important role where infants cannot acquire sufficient nutrition such as in low, middle-income and developing countries [17]. Multiple bioactive and immunomodulatory elements (antibodies and immunoglobulins) of HBM like miRNAs, cellular components (macrophages, T-cells and leukocytes), progenitor cells, growth-regulating hormones (somatostatin and calcitonin) epithelial cells and growth factors like vascular endothelial growth factor (VEGF), brain-derived neurotrophic factor (BDNF), glial cell-line-derived neurotrophic factor (GDNF), etc. show significant nutritional benefits in preclinical studies for adequate growth and development of infants $[18,19]$. Fats (long, short and medium-chain fatty acids (FA) and sphingomyelins), proteins (casein, osteopontin, peptides, cytokines, amylase, growth factors and haptocorrin), whey (alpha-lactalbumin, lactoferrin, lipases, lysozyme, sIgA and mucins) and carbohydrates (oligosaccharides and lactose) in HBM (Table 1) supplement energy, modulate immune system, neutralize toxins, absorb vitamins, stimulate brain and neural development, promote absorption of calcium, iron and phosphorus, inhibit pathogen attack and protect infants from antimicrobial and antiviral infections [6]. The supply of HBM to infants via breastfeeding is endorsed by WHO to render optimum nutrition for health and well-being of very low birth weight (VLBW) and preterm infants. Administration of HBM reduces hospitalization cost as it protects infants against healthcare-associated and communityrelated diseases like necrotizing enterocolitis (NEC), otitis media, neonatal sepsis, gastroenteritis and respiratory infections [15].

HBM offers several benefits to mothers like prevention of postpartum hemorrhage, amelioration of birth spacing and reduction in risk of ovarian and breast cancers [17]. Preterm HBM (PHBM) and THBM-derived exosomes show presence of peptides (lactadherin and lactotransferrin) and oligosaccharide 2'-fucosyllactose that protect infants against gastrointestinal diseases. HBM exosomes exhibit multiple beneficial effects like reduction in obesity and exacerbations of asthma, minimization of interleukin (IL)-2 and Tumor Necrotic Factor (TNF- $\alpha$ ) production and activation of T-regulatory cells [20]. Lactoferrin (glycoprotein) present in HBM possesses antimicrobial and immunomodulatory characteristics that protect infants against multiple infections by three mechanisms: 1 . Modulation of growth of bacteria in GIT, 2. Promotion of

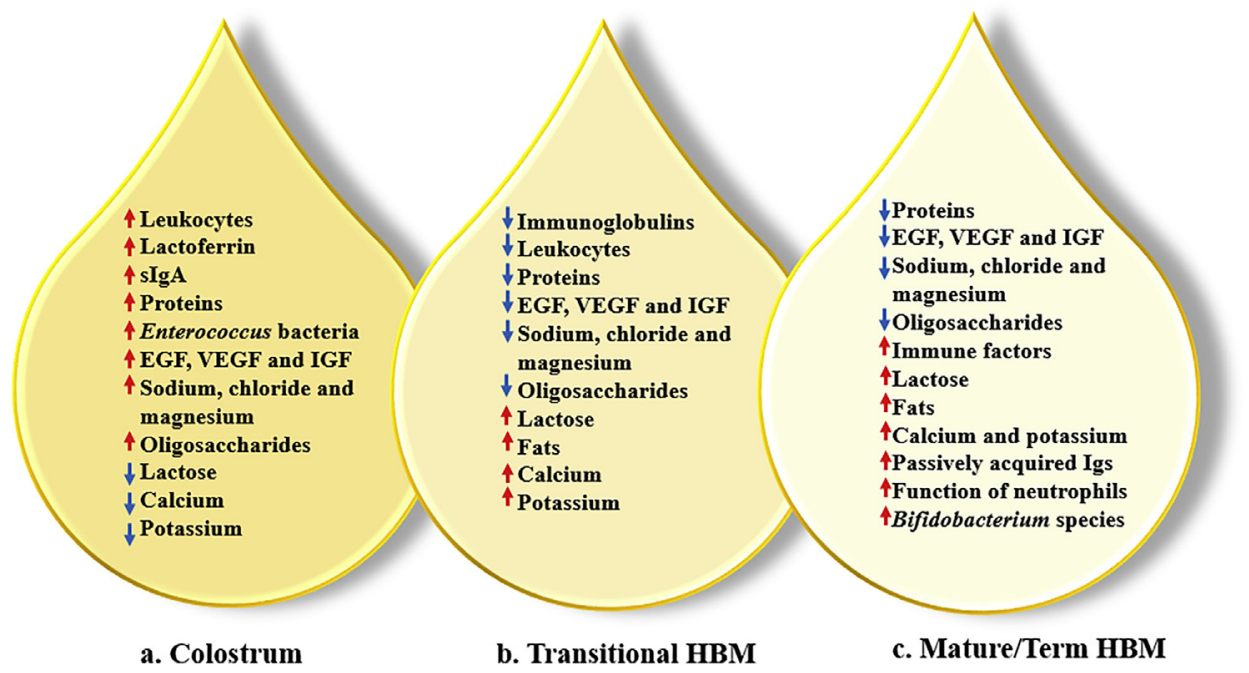

Fig. 1. Variability of nutritional components in: a. Colostrum, b. Transitional HBM and c. Mature/Term HBM. [sIgA: secretory Immunoglobulin A, EGF: Epidermal Growth Factor, VEGF: Vascular Endothelial Growth Factor, IGF: Insulin-like Growth Factor]. 
Table 1. Functions of fats, proteins, whey and carbohydrates in HBM.

\begin{tabular}{|c|c|c|}
\hline \multicolumn{2}{|c|}{ Components of HBM } & \multirow{2}{*}{$\begin{array}{l}\text { Functions } \\
\text { 1. Visual and neural development of infants }\end{array}$} \\
\hline \multirow[t]{9}{*}{ Fats } & Long-chain FA & \\
\hline & & 2. Modulation of immune system \\
\hline & & 3. Antiprotozoal and antiviral activities \\
\hline & Short-chain FA & 1. Source of energy \\
\hline & & 2. Maturation of GIT \\
\hline & Medium-chain FA & 1. Promotes peripheral glucose utilization \\
\hline & & 2. Source of energy \\
\hline & Sphingomyelins & 1. Myelination of central nervous system \\
\hline & & 2. Visual development of infants \\
\hline \multirow[t]{14}{*}{ Whey } & Lactoferrin & 1. Protects against iron-dependent pathogens \\
\hline & & 2. Antimicrobial activity \\
\hline & Secretory $\operatorname{IgA}$ & 1. Antipathogenic effect \\
\hline & & 2. Neutralizes toxins and viruses \\
\hline & Lysozyme & 1. Supports preterm growth of infants \\
\hline & & 2. Bactericidal and bacteriostatic effects \\
\hline & & 3. Promotes growth of commensal bacteria \\
\hline & $\alpha$-Lactalbumin & 1. Immunoprotective properties \\
\hline & & 2. Gut maturation and development \\
\hline & & 3. Promotes absorption of amino acids \\
\hline & & 4. Lactose synthesis \\
\hline & Bile salt-stimulated lipase & 1. Infant growth \\
\hline & & 2. Digestion of fats \\
\hline & Mucins & Inhibit binding of pathogens \\
\hline \multirow[t]{6}{*}{ Carbohydrates } & Oligosaccharides & 1. Antimicrobial, anti-infective and anti-adhesive properties \\
\hline & & 2. Prebiotic for gut colonization \\
\hline & & 3. Brain development in infants \\
\hline & Lactose & 1. Major source of energy \\
\hline & & 2. Prebiotic for gut colonization \\
\hline & & 3. Calcium absorption \\
\hline \multirow[t]{16}{*}{ Proteins } & Casein & 1. Source of calcium and phosphorous \\
\hline & & 2. Provide faster gastric transit than artificial formula milk \\
\hline & Peptides & Antihypertensive, antimicrobial, Antithrombotic and immunomodulatory activities \\
\hline & Osteopontin & 1. Immunomodulatory effects \\
\hline & & 2. Gut barrier functions \\
\hline & Amylase & 1. Antibacterial activity \\
\hline & & 2. Digestion of polysaccharides \\
\hline & Cytokines & 1. Anti-inflammatory effects \\
\hline & & 2. Anti-infective functions \\
\hline & Growth factors & 1. Promote intestinal growth and maturation of intestinal mucosa of infants \\
\hline & & 2. Anti-inflammatory effects \\
\hline & & 3. Stimulate growth of cells \\
\hline & & 4. Regulate development of multiple tissues and organs \\
\hline & & 5. Reduce effects of hypoxia, NEC, hemorrhagic shock, etc. \\
\hline & & 6. Develop neuronal system and enhance gut peristalsis \\
\hline & & 7. Enhance hematocrit level and stimulate erythropoiesis \\
\hline
\end{tabular}

proliferation of intestinal cells and 3. Differentiation, maturation and regulation of host-cell responses against pathogens [21]. HBM contains large quantities of immunoglobulin A (IgA) antibodies that demonstrate preventive effects against immunemediated diseases and bacterial skin infections by inhibiting the harmful microorganisms from penetrating the tissues and organs of infants [22]. Two categories of growth factors of HBM: 1. Transforming Growth Factors (TGF- $\alpha$ and TGF- $\beta$ ) and 2. Insulin-like Growth Factors (IGF-1 and IGF-2) stimulate wound healing and repair of cartilage and muscles. TGF- $\alpha$ and TGF- $\beta$ promote activities like cell proliferation, tissue and muscle repair, embryonic development and musculoskeletal growth, whereas IGF-1 induces anabolism, reduces catabolism and augments wound-healing properties [23]. Alpha-lactalbumin (component of HBM) enhances $\mathrm{Ca}^{2+}$ level, induces apoptosis and exhibits selective and specific cytotoxic activity. Thus, HBM plays a significant role in improvement of mucosal immunity, amelioration of antimicrobial activity and amplification of function of lymphocytes [6].

Cells of HBM are majorly divided into two classes: 1. Probiotic bacteria and 2. BM cells. Breast-derived cells (myoepithelial cells, lactocytes, stem cells and 
progenitor cells) and blood-derived cells (immunological and hemopoietic stem cells) are two major subclasses of BM cells (Fig. 2) [24]. Around $10^{7}-10^{8}$ bacterial cells in $800 \mathrm{~mL}$ of HBM are ingested by infants that help in development of their strong immune system with effective resistance against infectious diseases. Probiotic bacteria (Bifidobacteria and Lactobacilli) in HBM facilitate establishment of microbiome in infants, enhance nutritive value of $\mathrm{HBM}$ and enable use of HBM as an alternative to antibacterials and other antibiotics for the treatment of infections (mastitis and atopic dermatitis) in infants $[25,26]$. HBM is identified as a source for differentiation of neural cell lineage, thus indicating its involvement in the development of enteric nervous system which regulates the functions of GIT in infants. Human Breast Milk Stem Cells (hBSCs) exhibit application in regenerative medicine and assist in epigenetic regulation and development of tissues in infants. Easy and accessible harvesting of hBSCs via non-invasive techniques and negligible tumorigenic potential indicate their future use in autologous transplantation of tissues and organs in infants [27]. Useful constituents in HBM like probiotic and lactic acid bacteria, Bifidobacteria, Human Alpha-Lactalbumin Made Lethal To Tumour (HAMLET) cells, commensal bacteria and stem cells render natural antibacterial, anti-infectious and immunomodulatory properties to treat manifold skin problems (cuts, wounds, lesions and scrapes), skin irritations and allergies in infants [17].

Among nutrients present in HBM, triacylglycerides (TAGs) show highest amount of variability throughout lactation period $(8 \mathrm{~d}$ postpartum to 6 months). Palmitin-Olein-Olein (POO) and Palmitin-Olein-Linolein (POL) are two significant TAGs $(>49 \%)$ found in colostrum, wherein maternal factors like age, weight, gestational period, etc. do not affect concentrations of TAGs in HBM [16]. HBM reduces risk of sepsis, retinopathy and urinary tract infections, strengthens visual development in infants, promotes proliferation of diverse and well-balanced microbiota and suppresses immune-mediated complications like type 1 diabetes, inflammatory bowel disease and asthma [28]. Defensins and lactoferrin (in HBM) block the entry of harmful pathogens, preserve microbiota composition and promote action of good bacteria (Lactobacillus, Bacteroides, and Clostridia). The good bacteria are imperative in activation of neonatal immunologic functions like tolerance, maintenance of T-helper cell balance, mucus production, development of mucosal barrier homeostasis and promotion of tight junction expression [29]. IgA and IgG produced by B-cells in HBM exhibit antimicrobial protection against number of pathogens and post-natal virus acquisitions. HBM depicted significant neutralization potency for monoclonal

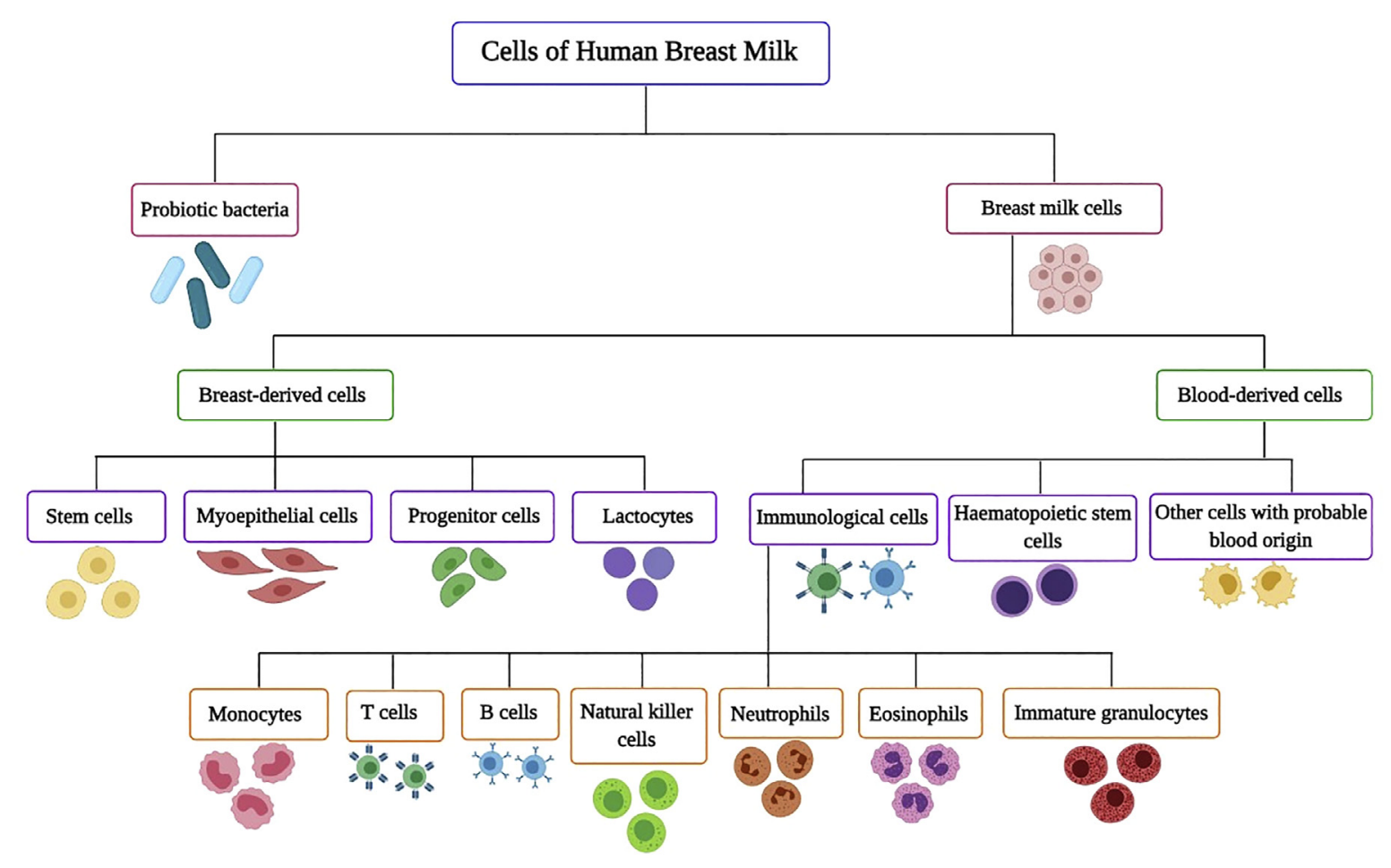

Fig. 2. Different types of cells present in HBM. 
antibodies (present in colostrum), anti-HIV-1 activity and inhibition of HIV transmission across mucosal barrier [30]. Free Secretory Component (FSC), an element of secretory $\operatorname{IgA}(\operatorname{sgA})$ found in $\mathrm{HBM}$, performs immune exclusion activity against pathogens to treat neonatal infections. FSC and sIgA inhibit attachment of pathogens on intestinal epithelial cells and neutralize their toxic effects in neonatal gut. Development of innate and adaptive immunities in infants, maintenance of integrity of intestinal epithelial barrier, regulation of mucosal homeostasis and inhibition of adhesion of Enteropathogenic Escherichia coli (EPEC) to epithelial cells suggest possible therapeutic effects of FSC for treatment of diarrhoea in infants [31]. HBM improves enteral feeding of preterm neonates, lowers incidences of vomiting and abdominal discomfort and shortens gastric residual time in comparison with formula-fed infants [17].

MicroRNAs are short (22 nucleotides) and fragile strands present in exosomes (extracellular vesicles) to regulate gene expression in humans. Researchers identified more than 1,400 miRNAs in HBM and suspected that they play a key role in modulating prominent aspects of child development like nutritional requirements and immune functions [18,32]. Evaluation of composition of PHBM revealed presence of higher concentration of metabolic miRNAs and macronutrients (protein and fats), suggesting that constitution of miRNA in HBM changes to help infants grow rapidly [33]. miR-335, miR-155, miR223, miR-375 and several other types of miRNAs are present abundantly in HBM and are responsible for epigenetic growth, development of immune and neuronal systems, reduction in allergies and prevention of autoimmune diseases in infants [17]. HBM miRNA (miR-148a-3p) acts as a biomarker for the preparation of artificial infant formulae, examination of breast aberrations, standardization and quality control of raw milk processing in dairy industry and evaluation of health status of lactating mother [34]. HBM miRNAs can be administered to infants via uptake of BM cells, exosomes and microvesicles or as free molecules in skim milk. Absorption of miRNAs will occur via gastrointestinal epithelial cells, followed by transport to tissues, organs and systemic circulation to perform immunoprotective and developmental programming functions [35]. Antioxidant capacity of HBM exhibited by bioactive proteins like lactoferrin, adiponectin, leptin and lysozyme indicate that it is an ideal source of nutrition for preterm infants. Antioxidant properties of HBM help to reduce oxidative stress-induced complications and reinforce immature antioxidant defense system of infants [4].

\subsection{Pre-clinical studies}

P-glycoprotein $\left(\mathrm{P}_{\mathrm{gp}}\right)$ deficiency causes NEC in newborn mice, whereas $P_{g p}$ induction protects epithelial cells from apoptosis mediated by pathogens. In a preclinical study, administration of HBM to newborn mice and rats resulted in increase of intestinal $P_{g p}$ levels on days 1-5 and 3-7, respectively. $\mathrm{HBM}$ stimulated $\mathrm{P}_{\mathrm{gp}}$-inducing factors like Epidermal Growth Factor (EGF), oligosaccharides, lactoferrin and heparin-binding EGF for potentiation of $\mathrm{P}_{\mathrm{gp}}$ expression in intestine and enterocyte cells of neonatal rodents to protect them from NEC [36]. In another preclinical study by Dai et al. [37] Human Milk Growth Factor III (HMGF III) derived from HBM demonstrated similar biological and chromatographic properties like EGF-urogastrone and reduced severity, duration and number of incidences of duodenal ulcer formation in CD-1 mice. A dose of $32 \mathrm{mg} / \mathrm{kg}$ of HMGF III resulted in substantial reduction of ulcer index (2.77 to 0.68$)$, incidence of ulcers $(62.50 \%$ to $18.18 \%)$ and severity score $(1.52 \pm 0.33$ to $0.32 \pm 0.228)$.

\subsection{Clinical studies}

Bio-active proteins in HBM show antioxidant properties that are beneficial for supply of adequate nutrition to preterm-born infants. The findings from clinical study conducted by Mehta et al. revealed that lactoferrin, leptin, lysozyme and adinopectin levels affect the Total Antioxidant Capacity (TAC) of HBM. Analysis of $60 \mathrm{HBM}$ samples from 15 women (21-43 years-of-age) showed significant effect of the proteins on HBM TAC $\left(\mathrm{R}^{2}=0.635 \pm 0.102, p<0.0001\right)$. Furthermore, higher concentrations of sIgA, adiponectin and lysozyme in transitional HBM and PHBM demonstrated their superior antibacterial and antiinflammatory activities in comparison to THBM [38]. Another clinical study revealed that PHBM rendered more nutritional and antimicrobial benefits (higher quantities of immunoglobulin A, sodium, potassium, chloride, lysozyme, proteins and lower quantities of fats, potassium and carbohydrates than THBM after first month of parturition. Levels of OPG, leptin and lactoferrin were higher in THBM $(p<0.05-0.0001)$ as compared to PHBM, indicating that THBM is imperative for neuroendocrine regulation [39]. Study of HBM-administered $(n=24)$ vs formula-fed infants $(n=15)$ depicted that IgA, lactoferrin and lysozyme content of HBM renders anti-infective and protective properties to infants. At 1 month $(p<0.025)$ and 7 months $(p<0.025)$ after discharge, infants who received HBM exhibited upper respiratory symptoms for fewer days in comparison to formula-fed 
infants [40]. Analysis of HBM (collected from 35 mothers) using filter-based mid-infrared (MIR) spectroscopy rendered quantification of macronutrient composition (amount of fats, lactose and proteins) of HBM. In comparison to Kjeldahl, Mojonnier and High-Performance Liquid Chromatography (HPLC) methods used for determination of proteins, fats and lactose, respectively, MIR spectroscopy emerged as easy and rapid point-of-care test (POCT) for evaluation of nutrients in HBM [41]. A clinical trial involving 1738 infants indicated that length of treatment and re-hospitalization rate for infants suffering from neonatal abstinence syndrome (NAS) were significantly decreased with administration of HBM $(n=430)$ in comparison to formula-fed infants ( $\mathrm{n}=1308)$ [42]. In another clinical study, administration of at least 50\% HBM to VLBW infants ( $\mathrm{n}=$ 202) for first two weeks (after birth) resulted in sixfold reduction of NEC ((OR $=0.17,95 \%$ CI: 0.04 to $0.68), p=0.01$ ) [43]. Deep sequencing technologybased study of 602 miRNAs originating from premiRNAs (precursors of miRNAs) revealed that about $67.82 \%$ of immune-related miRNAs are expressed in HBM exosomes. The miRNAs are transferred from HBM to GIT of infants and perform critical role in development of strong immune system. Unsuitable conditions like RNase-mediated digestion, prolonged incubation of miRNAs at room temperature and exposure to multiple freeze-thaw cycles did not affect stability and functions of the miRNAs [44]. DNA samples were extracted from $\mathrm{HBM}$ and subjected to amplification to examine clinical use of DNA in pharmacogenetic studies. The experiment revealed that unpasteurized HBM served as an alternative to blood for pharmacogenetic analysis and suggested enhancement in administration of HBM to infants for improving their nutritional requirements [45]. Data of clinical and preclinical studies using HBM is illustrated in Table 2.

\section{Future implications of pediatric drug delivery via HBM}

Drug delivery to pediatric population demonstrates considerable variability in age, weight,

Table 2. Data of clinical and preclinical studies using HBM.

\begin{tabular}{|c|c|c|c|c|c|}
\hline Sr. No. & Objective & Study design & Result & Interpretation & Reference \\
\hline \multicolumn{6}{|c|}{ Pre-clinical studies } \\
\hline 1. & $\begin{array}{l}\text { To understand HBM- } \\
\text { induced Pgp expression } \\
\text { for protection against NEC } \\
\text { in neonates }\end{array}$ & $\begin{array}{l}\text { Postpartum Sprague- } \\
\text { Dawley rats and newborn } \\
\text { rats were studied. } \\
\text { 1. HBM was obtained from } \\
\text { healthy volunteers and } \\
\text { centrifuged to remove } \\
\text { insoluble matter and } \\
\text { lipids }\end{array}$ & $\begin{array}{l}\text { 1. Low } P_{g p} \text { levels were } \\
\text { identified as cause of NEC } \\
\text { in newborn rodents. } \\
\text { 2. Intestinal epithelium of } \\
\text { rodents was protected } \\
\text { against bacterial } \\
\text { colonization and NEC due } \\
\text { to supply of HBM. }\end{array}$ & $\begin{array}{l}\text { Administration of HBM } \\
\text { decreases the risk of NEC } \\
\text { in newborns and protects } \\
\text { against NEC. }\end{array}$ & [36] \\
\hline 2. & $\begin{array}{l}\text { To study effect of HBM- } \\
\text { derived HMGF-III on } \\
\text { duodenal ulcers induced } \\
\text { in mice }\end{array}$ & $\begin{array}{l}\text { Duodenal ulcers in male } \\
\text { CD-1 mice were induced } \\
\text { by cysteamine } \mathrm{HCl} \text {, } \\
\text { followed by treatment } \\
\text { with HMGF-III }\end{array}$ & $\begin{array}{l}\text { Number of incidences, } \\
\text { ulcer index and severity } \\
\text { score of duodenal ulcers } \\
\text { in CD- } 1 \text { mice were } \\
\text { reduced }\end{array}$ & $\begin{array}{l}\text { HMGF-III exhibited } \\
\text { protective effect on } \\
\text { cysteamine-induced } \\
\text { duodenal ulcers in CD-1 } \\
\text { mice. }\end{array}$ & [37] \\
\hline \multicolumn{6}{|c|}{ Clinical Trials } \\
\hline 1. & $\begin{array}{l}\text { To study the effect of bio- } \\
\text { active proteins on TAC of } \\
\text { HBM }\end{array}$ & $\begin{array}{l}\text { 1. PHBM samples: } 60 \\
\text { 2. THBM samples: } 20\end{array}$ & $\begin{array}{l}\text { 1. Content of bio-active } \\
\text { proteins affects the TAC of } \\
\text { HBM }\left(\mathrm{R}^{2}=0.635 \pm 0.102 \text {, }\right. \\
p=0.0001) \\
2 \text {. Higher levels of } \\
\text { adiponectin, IgA and } \\
\text { lysozyme in PHBM } \\
\text { 3. Higher level of OPG, } \\
\text { leptin and lactoferrin in } \\
\text { THBM }\end{array}$ & $\begin{array}{l}\text { 1. Antioxidant activity of } \\
\text { HBM is enhanced due to } \\
\text { presence of bio-active } \\
\text { proteins, thus rendering } \\
\text { HBM as an ideal nutritive } \\
\text { supplement for infants } \\
\text { 2. PHBM exhibited higher } \\
\text { levels of proteins } \\
\text { (adinopectin, IgA and } \\
\text { lysozyme) that show anti- } \\
\text { inflammatory and } \\
\text { antibacterial activities } \\
\text { 3. PHBM showed lower } \\
\text { level of leptin indicating } \\
\text { improper neuroendocrine } \\
\text { regulation }\end{array}$ & {$[38]$} \\
\hline
\end{tabular}


Table 2. (continued)

\begin{tabular}{lllll}
\hline Sr. No. & Objective & Study design & Result & Interpretation \\
\hline 2. & To analyze effect of & 1. PHBM samples: 60 & 1. Reduction in levels of & PHBM renders better \\
& $\begin{array}{l}\text { content of bioactive } \\
\text { proteins in PHBM and }\end{array}$ & 2. THBM samples: 20 & $\begin{array}{l}\text { OPG, lysozyme, } \\
\text { adiponectin and }\end{array}$ & $\begin{array}{l}\text { antimicrobial and anti- } \\
\text { inflammatory properties }\end{array}$ \\
THBM & & $\begin{array}{l}\text { lactoferrin, adiponectin } \\
\text { than THBM, whereas }\end{array}$ & $\begin{array}{l}\text { was observed but no } \\
\text { change in sIgA content }\end{array}$ & $\begin{array}{l}\text { PHBM helps in } \\
\text { neuroendocrine }\end{array}$ \\
& & was reported in PHBM & regulation of infants
\end{tabular}

3. To examine effect of HBM in reduction of symptoms of infections

4. To validate MIR spectroscopy for analysis of macronutrients in HBM

5. To assess benefit of HBM (administered to infants) in shortening duration of pharmacological treatment for NAS and length of hospitalization of infants

6. To test whether administration of HBM $(\geq 50 \%)$ for first 14 days after birth is protective against NEC in VLBW infants

7. To understand expression of immune-related miRNAs in HBM exosomes

8.

To assess possibility of DNA extraction from HBM for pharmacogenetic studies
24 infants: Administered

HBM

15 infants: Administered milk formula

HBM samples collected from 35 mothers to assess quantities of fats, lactose and proteins

1738 HBM-fed infants analyzed. Infants were divided into 3 main groups: 1. No HBM group, 2. HBM group and 3. Formula-fed/any BM group 222 VLBW infants divided into 2 groups: $1 .<50 \%$ HBM administration $(\mathrm{n}=$ 46) 2. $\geq 50 \% \mathrm{HBM}$ administration $(\mathrm{n}=156)$

602 miRNAs from 452 premiRNAs were studied from 20-30 mL HBM samples

HBM samples (74) obtained from 37 mothers, of which some were subjected to pasteurization. Amplification of DNA performed using PCR technique and THBM in the first month of lactation. 2. Levels of OPG, leptin and lactoferrin were higher in THBM $(p<0.05-$ 0.0001 ) as compared to PHBM

Decrease in duration of upper respiratory in infants after one month post discharge $(p<0.025)$ and at seven months $(p<0.025)$

ICC for fats: 0.997 , lactose: 0.776 and proteins: 0.839

Median duration of treatment and hospitalization was found to be lower in HBM-fed infants than no HBM-fed infants

1. $5 / 46(10.6 \%)$ infants affected with NEC in first group

2. $5 / 156(3.2 \%)$ infants affected with NEC in second group

59 out of $87(67.82 \%)$ immune-related premiRNAs contain HBM exosomes $(p<10-16)$

Mean DNA concentration in:

1. Pasteurized HBM samples: $2.0 \pm 1.8 \mathrm{ng} / \mu \mathrm{L}$ 2. Unpasteurized HBM samples: $2.6 \pm 2.0 \mathrm{ng} / \mu \mathrm{L}$
HBM reduces symptoms of upper respiratory infection in infants in first year after birth

MIR spectroscopy is an effective method for analysis of macronutrients in HBM HBM decreased duration of pharmacological treatment for NAS and hospitalization stay

$\geq 50 \%$ administration of HBM for first $14 \mathrm{~d}$ after birth resulted in sixfold reduction of risk of NEC

1. HBM exosomal miRNAs are transported to infants via GIT

2. These exosomes are resistant harsh extracellular environmental conditions DNA extraction from HBM is possible and shows ability to serve as source of DNA for pharmacogenetic studies
[40]

HMGF III: Human Milk Growth Factor II,
action, TAC: Total Antioxidant Capacity.

disease condition, health status, degree of physiological and psychological development, etc. [3]. Differences in transportation and metabolism of drugs and lack of safer and biocompatible drugcarrier systems for pediatric patients generate the need for HBM-based drug carriers. Bovine milkderived exosomes serve as carriers for lipophilic and hydrophilic drugs (withaferin, anthocyanidin, docetaxel, curcumin and paclitaxel), anti-cancer agents and small molecules for efficacious activity 
against lung tumors [46]. The exosomes demonstrated protective effects against inflammatory diseases, boosted immunity in infants, improved targeting of anticancer drugs for tumors and exhibited cross-species tolerance with minimum side effects. Improvisation of oral bioavailability, enhancement of safety and efficacy of drugs and increase in biocompatibility, physical and biological stability, tolerability and cost-effective scalability for large-scale manufacturing were some predominant functions demonstrated by bovine milk-derived exosomes [46]. HBM was found to contain mRNA transcripts embedded in microvesicles that enabled transfer of genomic information from mother to infant during breastfeeding. The microvesicles exhibited reverse transcription activity, followed by integration into genome of infants to permanently rectify clinical manifestations of genetic diseases [47]. HBM microvesicles enhanced acceptance of allografts and showed tolerance to Major Histocompatibility Complex (MHC) antigens transferred from mother to infant after breastfeeding. The microvesicles displayed stability in extracellular environment, maintained their structure and function at low $\mathrm{pH}$ in stomach and exhibited resistance to enzymatic degradation by pepsin. Due to such effective functional properties of HBM microvesicles, their use as gene delivery vehicles for treatment of genetic diseases in infants is encouraged [47,48]. Isolation and engineering of HBM cells as potent vehicles for rapid and painless drug and gene delivery can facilitate tissue and organ-specific treatments for diseases in infants. Modulation of immune cells of HBM (for delivery of vaccines), stem cells (for prevention of birth defects) and epithelial cells (for production of specific proteins) in order to alter genetic diseases are some advanced approaches suggested for drug delivery to infants [48]. Collection of milk from mother with sick child, isolation of cells from BM, transfection of these cells with modified DNA, incubation of cells (for their growth and division), transfer of cells back to BM and finally administration of this modified $\mathrm{BM}$ to infants will result in fortification of nutritive value delivered to infants (Fig. 3). Epithelial cells of HBM produce large quantities of specific type of RNA that prevents translation of mRNAs into proteins and controls expression of maternal genes. Thus, epithelial cells in BM (also called as "proteinreplacement factories") show capability of integration into tissues and organs of breastfed infants resulting in reinforcement of their growth and development [7]. A four-month-old infant can consume more than 100 million cells of HBM (during breastfeeding) everyday; however, it is extremely difficult to deliver large macromolecules into GIT of infants due to limited intestinal permeability. However, HBM cells with $1000 \mathrm{X}$ larger size

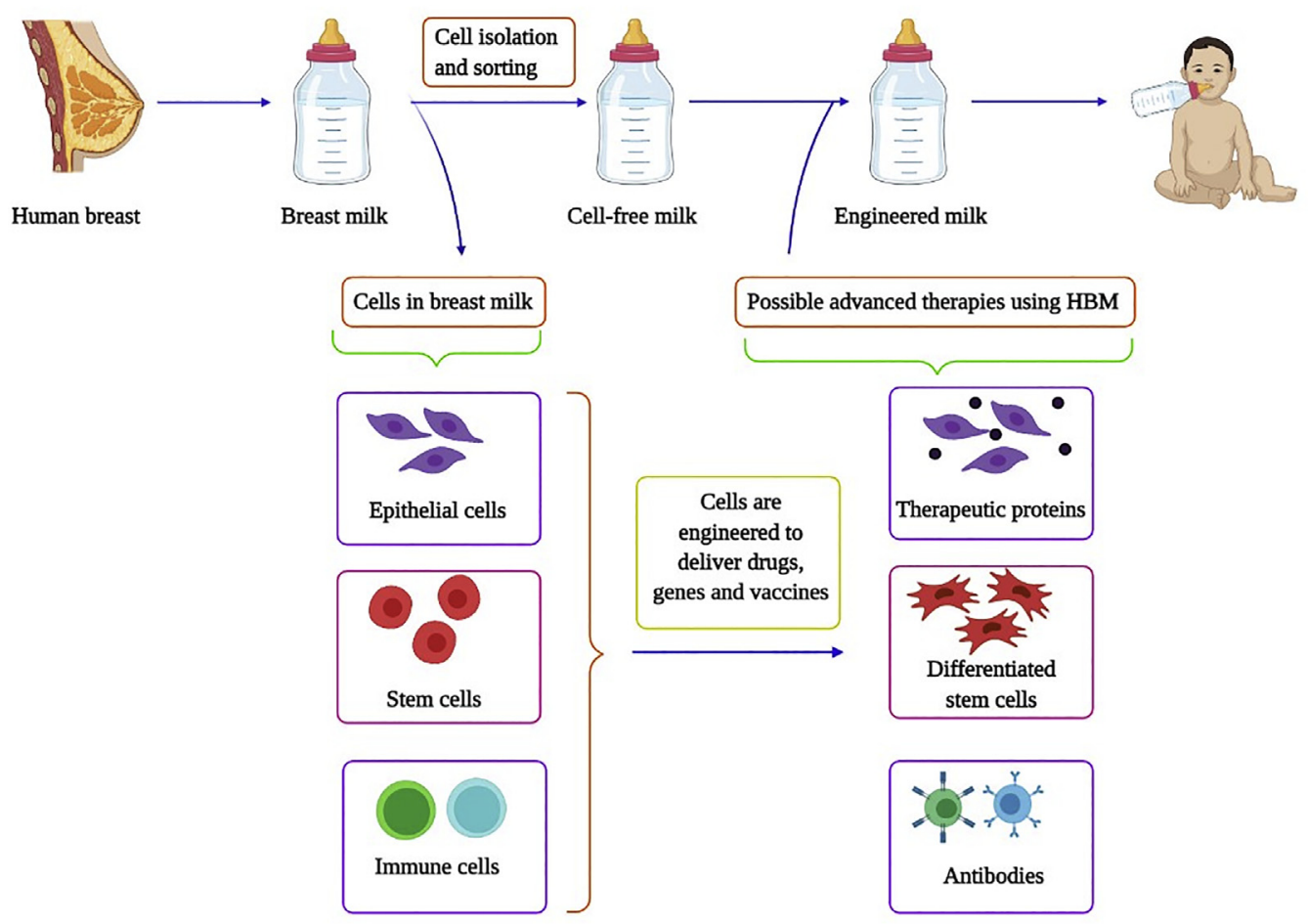

Fig. 3. Engineering HBM cells for development of drug delivery systems for infants. 
than macromolecules are efficiently transported to GIT where they remain intact and proliferate without degradation [5]. Stem cells in HBM show potential to transform into any other cell in body of infants, thus, they show potential in development of regenerative medicine and generation of efficient systems to deliver drugs and vaccines for cure and prevention of untreatable diseases in infants [27]. Delivery of HBM-derived cells to specific locations in infant body is predicted to enable manifestation of specific therapeutic effects with lesser toxicity in comparison to other synthetic drug delivery systems $[48,49]$.

\section{Conclusions}

Nutritional deficiencies in pediatrics increase risk of respiratory and gastrointestinal infections, brain and neural impairment, improper growth and immunological disorders. HBM is a natural biofluid composed of manifold bioactive macromolecules that fulfill nutritional requirements of infants, strengthen their growth and development processes and protect them from infectious diseases. Colostrum demonstrates more benefits than term breast milk and protects infants in initial days of life as it contains higher amounts of growth and immune factors. Exosomes derived from HBM show significant anti-infective activity, immunomodulatory properties and anti-cancer effects with possibility to function as carriers for drug delivery to infants. Several types of miRNAs are considered as key components of HBM due to their ability to exhibit both therapeutic and diagnostic properties. Development of regenerative medicine and use of drug, vaccine and gene delivery systems for infants to render specific treatment of untreatable diseases is possible via effective manipulations in stem cells, immune cells and epithelial cells of HBM. In the future, greater knowledge and advancement in research on HBM will aid in conceptualization of novel therapeutic applications to reinforce overall growth and development of infants.

\section{Conflict of interest}

The authors declare that there are no conflicts of interest.

\section{References}

[1] Saunders J, Smith T, Stroud M. Malnutrition and undernutrition. Medicine 2011;39:45-50.

[2] World Health Organization. Health topics. Malnutrition. Available at https://www.who.int/health-topics/malnutrition \#tab=tab_1. [Accessed 17 January, 2021].
[3] UNICEF. What Are The Challenges?. Available at https:// www.unicef.org/nutrition/index_challenges.html. [Accessed 17 January, 2021].

[4] Cooper AR, Barnett D, Gentles E, Cairns L, Simpson JH. Macronutrient content of donor human breast milk. Arch Dis Child Fetal Neonatal Ed 2013;98:F539-41.

[5] Human milk: Bioactive components and their effects on the infant and beyond. Available at https://assets.pubpub.org/ yxihmn47/11597062490277.pdf. [Accessed 17 January, 2021].

[6] Andreas NJ, Kampmann B, Le-doare KM. Early human development human breast milk: A review on its composition and bioactivity. Early Hum Dev 2015;91:629-35.

[7] Hassiotou F, Geddes DT, Hartmann PE. Cells in human milk: State of the science. J Hum Lact 2013;29:171-82.

[8] Muthayya S, Rah JH, Sugimoto JD, Roos FF, Kraemer K, Black RE. The global hidden hunger indices and maps: An advocacy tool for action. PLoS One 2013;8:1-12.

[9] UNICEF. Available at https://www.unicef.org/media/60806/ file/SOWC-2019.pdf. [Accessed 30 August, 2020].

[10] Lifshitz F. Nutrition and growth - Review. J Clin Res Pediatr Endocrinol 2009;1:157-63.

[11] Lawrence RA. Breastfeeding: Benefits, risks and alternatives. Curr Opin Obstet Gynecol 2000;12:519-24.

[12] Gartner LM, Morton J, Lawrence RA, Naylor AJ, O'Hare D, Schanler RJ, et al. Breastfeeding and the use of human milk. Pediatrics 2005 Feb 1;115:496-506.

[13] Kumar RK, Singhal A, Vaidya U, Banerjee S, Anwar F, Rao S. Optimizing nutrition in preterm low birth weight infants-Consensus summary. Front Nutr 2017;4:1-9.

[14] Brooke OG, Alvear J, Arnold M. Energy retention, energy expenditure, and growth in healthy immature infants. Pediatr Res 1979;13:215-20.

[15] Prentice P, Ong KK, Schoemaker MH, Van Tol EAF, Vervoort J, Hughes IA, et al. Breast milk nutrient content and infancy growth. Acta Paediatr Int J Paediatr 2016;105:641-7.

[16] Folgoso CC, Lo MC, Sabater A, Pons SM, Bargallo AC. Triacylglycerol composition in colostrum, transitional and mature human milk. 2000. p. 878-82.

[17] Witkowska-Zimny M, Kamińska-El-Hassan E, Wróbel E. Milk therapy: Unexpected uses for human breast milk. Nutrients 2019 May;11:944.

[18] Tomé-carneiro J, Fernández-alonso $N$, Tomás-zapico $C$ Visioli F, Iglesias-gutierrez E, Dávalos A. Breast milk microRNAs harsh journey towards potential effects in infant development and maturation. Lipid encapsulation can help. Pharmacol Res 2018;132:21-32.

[19] Hassiotou F, Geddes DT. Immune cell-mediated protection of the mammary gland and the infant during breastfeeding. Advances in Nutrition 2015 May;6:267-75.

[20] Galley JD, Besner GE. The Therapeutic potential of breast milk-Derived extracellular vesicles. Nutrients 2020;12:745.

[21] Ochoa TJ. Is lactoferrin still a treatment option to reduce neonatal sepsis? ADHD management during the COVID-19 pandemic: guidance from the European ADHD Guidelines Group. Lancet Child Adolesc Heal 2020;4:411-2.

[22] Telemo E, Hanson LA. Antibodies in milk. J Mammary Gland Biol Neoplasia 1996;1:243-9.

[23] Allam NA, Wafa A, Talat AM. The effect of topical application of mother milk on separation of umbilical cord for newborn babies. Am J Nurs 2015;4:288-96.

[24] Witkowska-Zimny M, Kaminska-El-Hassan E. Cells of human breast milk. Cell Mol Biol Lett 2017;22:1-1.

[25] Lara-Villoslada F, Olivares M, Sierra S, Miguel Rodríguez J, Boza J, Xaus J. Beneficial effects of probiotic bacteria isolated from breast milk. Br J Nutr 2007;98:96-100.

[26] Boix-Amorós A, Collado MC, Mira A. Relationship between milk microbiota, bacterial load, macronutrients, and human cells during lactation. Front Microbiol 2016;7:1-9.

[27] Ninkina N, Kukharsky MS, Hewitt MV, Lysikova EA, Skuratovska LN, Deykin AV, et al. Stem cells in human breast milk. Hum Cell 2019;32:223-30.

[28] Wight NE. Donor human milk for preterm infants. J Perinatol 2001;21:249-54. 
[29] Walker WA, Iyengar RS. Breast milk, microbiota, and intestinal immune homeostasis. Pediatr Res 2015;77:220-8.

[30] Jeffries TL, Sacha CR, Pollara J, Himes J, Jaeger FH, Dennison SM, et al. The function and affinity maturation of HIV-1 gp120-specific monoclonal antibodies derived from colostral B cells. Mucosal Immunol 2016;9:414-27.

[31] Demers-Mathieu V, Mathijssen G, Dapra C, Do DM, Medo E. Active free secretory component and secretory $\operatorname{IgA}$ in human milk: do maternal vaccination, allergy, infection, mode of delivery, nutrition and active lifestyle change their concentrations? Pediatr Res 2020;20:1-8.

[32] Zecca E, Zuppa AA, Antuono AD, Tiberi E, Giordano L, Pianini T, et al. Efficacy of a galactogogue containing silymarin-phosphatidylserine and galega in mothers of preterm infants : a randomized controlled trial. Eur J Clin Nutr 2016: $1151-4$.

[33] Kosaka N, Izumi H, Sekine K, Ochiya T. MicroRNA as a new immune-regulatory agent in breast milk. Silence 2010;1:7.

[34] Rubio M, Bustamante M, Hernandez-Ferrer C, FernandezOrth D, Pantano L, Sarria Y, et al. Circulating miRNAs, isomiRs and small RNA clusters in human plasma and breast milk. PLoS One 2018;13:1-19.

[35] Melnik BC, Kakulas F, Geddes DT, Hartmann PE, John SM, Carrera-Bastos P, et al. Milk miRNAs: Simple nutrients or systemic functional regulators? Nutr Metab 2016;13:1-5.

[36] Guner YS, Franklin AL, Chokshi NK, Castle SL, Pontarelli E, Wang J, et al. P-glycoprotein induction by breast milk attenuates intestinal inflammation in experimental necrotizing enterocolitis. Lab Investig 2011;91:1668-79.

[37] Dai S, Klagsbrun M, Shing YW. Human milk-derived growth factor prevents duodenal ulcer formation. Pediatr Res 1985; 19:916-8.

[38] Mehta R, Petrova A. Is variation in total antioxidant capacity of human milk associated with levels of bio-active proteins? J Perinatol 2014;34:220-2.

[39] Mehta R, Petrova A. Biologically active breast milk proteins in association with very preterm delivery and stage of lactation. J Perinatol 2011:58-62.
[40] Bier JB, Oliver T, Ferguson A, Vohr BR. Human milk reduces outpatient upper respiratory symptoms in premature infants during their first year of life. J Perinatol 2002;22:354-9.

[41] Parat S, Groh-Wargo S, Merlino S, Wijers C, Super DM. Validation of mid-infrared spectroscopy for macronutrient analysis of human milk. J Perinatol 2017;37:822-6.

[42] Favara MT, Carola D, Jensen E, Cook A, Genen L, Dysart K, et al. Maternal breast milk feeding and length of treatment in infants with neonatal abstinence syndrome. J Perinatol 2019; 39:876-82.

[43] Sisk PM, Lovelady CA, Dillard RG, Gruber KJ, Shea TMO. Early human milk feeding is associated with a lower risks of necrotizing enterocolitis in very low birth weight infants. J Perinatol 2007:428-33.

[44] Zhou Q, Li M, Wang X, Li Q, Wang T, Zhu Q, et al. Immunerelated microRNAs are abundant in breast milk exosomes. Int J Biol Sci 2012;8:118.

[45] Douglas CA, Ivey KL, Papanicolas LE, Best KP, Muhlhausler BS, Rogers GB. DNA extraction approaches substantially influence the assessment of the human breast milk microbiome. Sci Rep 2020;1-10.

[46] Munagala R, Aqil F, Jeyabalan J, Gupta RC, Graham J, Cancer B. Bovine milk-derived exosomes for drug delivery. Cancer letters 2016;371:48-61.

[47] Irmak MK, Oztas Y, Oztas E. Integration of maternal genome into the neonate genome through breast milk mRNA transcripts and reverse transcriptase. Theor. Biol. Medical Model. 2012;9:1-8.

[48] Chemical, Engineering News. These scientists want to engineer breast-milk cells to deliver drugs to babies. Here's how. Available at https://cen.acs.org/pharmaceuticals/drugdelivery/scientists-ambitious-plan-Engineer-breast/97/i9\#: $\sim:$ text=Katie $\%$ 20Whitehead's $\% 20$ plan $\% 20$ to $\% 20$ turn,them $\%$ 20to $\% 20 \mathrm{a} \% 20$ sick $\% 20$ infant. [Accessed 17 January, 2021].

[49] Alsaweed M, Lai CT, Hartmann PE, Geddes DT, Kakulas F. Human milk cells contain numerous miRNAs that may change with milk removal and regulate multiple physiological processes. Int J Mol Sci 2016;17. 